\title{
Formation of Gd-Al Alloy Films by a Molten Salt Electrochemical Process
}

\author{
Concha Caravaca and Guadalupe De Córdoba \\ CIEMAT, Departamento de Energía/División de Fisión Nuclear/URAA, Avda. Complutense, 22, \\ Madrid, 28040, Spain \\ Reprint requests to Dr. C. C.; Fax: +34-91-3466233; E-mail: c.caravaca@ ciemat.es \\ Z. Naturforsch. 63a, 98 - 106 (2008); received December 1, 2006 \\ Presented at the EUCHEM Conference on Molten Salts and Ionic Liquids, Hammamet, Tunisia, \\ September 16-22, 2006.
}

\begin{abstract}
The electrochemistry of molten $\mathrm{LiCl}-\mathrm{KCl}-\mathrm{GdCl}_{3}$ at a reactive $\mathrm{Al}$ electrode has been studied at 723 to $823 \mathrm{~K}$. Electrochemical techniques such as cyclic voltammetry and chronopotentiometry have been used in order to identify the intermetallic compounds formed. Cyclic voltammetry showed that, while at an inert $\mathrm{W}$ electrode $\mathrm{GdCl}_{3}$ is reduced to $\mathrm{Gd}$ metal in a single step at a potential close to the reduction of the solvent, at an $\mathrm{Al}$ electrode a shift towards more positive values occurs. This shift of the cathodic potential indicated a reduction of the activity of $\mathrm{Gd}$ in $\mathrm{Al}$ with respect to that of $\mathrm{W}$, due to the formation of alloys. The surface characterization of samples formed by both galvanostatic and potentiostatic electrolysis has shown the presence of two intermetallic compounds: $\mathrm{GdAl}_{3}$ and $\mathrm{GdAl}_{2}$. Using open-circuit chronopotentiometry it has been possible to measure the potentials at which these compounds are transformed into each other. The values of these potential plateaus, once transformed into e.f. m. values, allowed to determine the thermodynamic properties of the $\mathrm{GdAl}_{3}$ intermetallic compound.
\end{abstract}

Key words: Molten Salts; Gadolinium; Electrolysis; Alloy Formation; Pyrochemical Processes.

\section{Introduction}

For future innovative reactor systems an important criterion to be taken into account is the sustainability, including minimization of waste output and its radiotoxicity. The most radiotoxic actinoides $(\mathrm{Pu}, \mathrm{Np}$, $\mathrm{Am}$ and $\mathrm{Cm}$ ) have a great impact, therefore their recycling is compulsory $[1,2]$.

Over the last few years a huge amount of research has been carried out worldwide with the aim of separating these actinoides and transmuting them, in dedicated nuclear reactors, into stable or shortlived radionuclides. Processes that are considered use both electrochemical (electrorefining and/or electrolysis) and reductive salt extraction/metal techniques. The molten salt media under study are mainly chlorides and fluorides of alkali and alkaline earth metals. Some of the advantages of these high-temperature processes are the radiation resistance of the salt and metal phases used, that allows a high actinoide content in the medium and short cooling times, and their inherent proliferation resistance.

Special attention has been paid to the separation of actinoides (An) from lanthanoides ( $\mathrm{Ln})$ due to their similar chemical properties that make their separation quite difficult. Due to the neutronic poison effect of some of the lanthanoides their allowed content in future nuclear fuel has to be kept low.

For homogeneous recycling of all actinoides, pyrochemical processes involving high temperature, using molten salt and metal phases, are considered as a promising alternative to hydrometallurgical processes. Thermodynamic calculations have shown that aluminium could be a promising metallic solvent to support the grouped recovery of An with an efficient separation from Ln [3,4]. In chloride media, the An-Ln separation is being developed using electrochemical techniques. In order to develop a future nuclear cycle, the understanding of the chemical and electrochemical behaviour of the actinoides and lanthanoides is necessary. This includes a good knowledge of both the thermodynamic and kinetic properties of the different elements contained in the spent nuclear fuel, in the salt and metal phases. Among the lanthanoides, the study of the gadolinium behaviour is interesting because of its significant content in the spent nuclear fuel and its reduction potential in molten $\mathrm{LiCl}-\mathrm{KCl}$, that is close to 
those of An, which makes difficult the selective separation.

The electrochemical behaviour of $\mathrm{Gd}$ in $\mathrm{LiCl}-\mathrm{KCl}$ at inert cathodes has already been studied at CIEMAT [5] and several other places [6-9]. The present paper is the continuation of the systematic determination of the basic properties of actinoides and fission products that is being carried out at CIEMAT within the EUROPART project of the European Commission. The present work deals with the identification and characterization of the $\mathrm{Gd}-\mathrm{Al}$ intermetallic compounds in the molten eutectic $\mathrm{LiCl}-\mathrm{KCl}$, which have been carried out using the technique of open-circuit chronopotentiometry and performing electrolyses at constant potential and current at Al plates. The characterization of the alloys formed, performed by different techniques, showed the formation of the intermetallic compounds $\mathrm{GdAl}_{3}$ and $\mathrm{GdAl}_{2}$, depending on the potential applied. The determination of the thermodynamic properties of $\mathrm{GdAl}_{3}$ has been performed by e.m.f. measurements. Comparison of the present results with those found in the literature [9] showed good agreement both in the thermodynamic data and also in the two intermetallics identified.

\section{Experimental}

Storage and handling of the chemicals was carried out in a glovebox under pure $\operatorname{Ar}(\mathrm{g})$ (Air Liquide; $\mathrm{H}_{2} \mathrm{O},<0.5 \mathrm{ppm}$, and $\mathrm{O}_{2},<0.1 \mathrm{ppm}$ ). Electrochemical experiments were performed in a sealed quartz cell under $\operatorname{Ar}(\mathrm{g})$, additionally purified by passing through both a moisture and an oxygen trap (Agilent). The thermocouple and electrodes were positioned in a cell which also supported a vitreous carbon crucible (Sofacel S.A.) containing the electrolyte.

The electrolyte was the eutectic $\mathrm{LiCl}-\mathrm{KCl}$ (59: $41 \mathrm{~mol} \%$ ) (Aldrich, 99\% - Merck, 99.999\%). The preparation of $\mathrm{LiCl}-\mathrm{KCl}$ was performed by heating a mixture at $200{ }^{\circ} \mathrm{C}$ under vacuum for $22 \mathrm{~h}$ before melting. The temperature was then raised to $450{ }^{\circ} \mathrm{C}$ under $\operatorname{Ar}(\mathrm{g})$. Once melted, the bath was purified by $\mathrm{HCl}(\mathrm{g})$ treatment (Air Liquide; $\mathrm{H}_{2} \mathrm{O},<10 \mathrm{ppm}$ ) for 45-60 min, followed by $\operatorname{Ar}(\mathrm{g})$ sparging in order to remove the dissolved $\mathrm{HCl}(\mathrm{g})$.

Solutions of $\mathrm{GdCl}_{3}$ (Aldrich, 99.99\%) were prepared by direct addition of anhydrous trichlorides without further treatment.

The electrochemical study has been performed using a three electrode set-up with a potentiostat- galvanostat Autolab PGSTAT30 (Eco-Chimie) controlled with an Autolab GPES software v.4.9.

Metallic inert tungsten $(\varnothing 1 \mathrm{~mm}$, Goodfellow $99.9 \%)$ and solid reactive aluminium $(\varnothing 1 \mathrm{~mm}$, Aldrich, 99.999\%) wires, and Al plates (0.5 and $1 \mathrm{~mm}$ thickness, Aldrich, 99.999\%) were used as working electrodes. Before the electrochemical measurements the working electrodes were rinsed with ethanol in an ultrasonic bath. The surface area of the electrodes was determined after each experiment by measuring the immersion depth into the molten salt.

The reference electrode consisted of an $\mathrm{Ag}$ wire ( $\varnothing 1 \mathrm{~mm}$, Aldrich, 99.99\%) dipped in a closed-end Pyrex glass tube containing a $0.75 \mathrm{~mol} \mathrm{~kg}^{-1} \mathrm{AgCl}$ (Merck, 99.4\%) solution in LiCl-KCl. The counter electrodes consisted of vitreous either carbon or graphite rods ( $\varnothing 3 \mathrm{~mm}$, Sofacel S. A.).

Gd-Al alloy samples were washed either with water and then ethanol or with a mixture of ethanol/water $(80: 20 \mathrm{vol} \%)$ in an ultrasonic bath in order to remove the residual salt before the surface analysis. This procedure has been used by Nohira et al. for Pr-Ni alloys [10], and it has been applied for $\mathrm{Gd}-\mathrm{Al}$ since Colinet indicated that $\mathrm{Gd}-\mathrm{Al}$ compounds, especially those rich in $\mathrm{Al}$, are very stable [11].

Surface analysis of the Gd-Al alloys formed was performed by X-ray diffraction (XRD) (X'Pert, MPD Philips), using $\mathrm{Cu}$ as anode, in order to identify the intermetallic compounds formed during the electrolysis. Also the techniques of scanning electron microscopy (SEM) with energy dispersive X-ray (EDX) analysis incorporated (Hitachi S-2500, $30 \mathrm{kV}$ ) were used to determine the surface composition and the concentration profiles of Gd in the alloy layer.

The determination of the concentration was performed by taking samples of the melt diluting them in nitric acid solutions ( 1 vol\%), and analysing them by ICP-MS.

\section{Results and Discussion}

According to the Gd-Al phase diagram [12] (see Fig. 1), Gd can form 5 solid intermetallic compounds with aluminium: $\mathrm{AlGd}_{2}, \mathrm{Al}_{2} \mathrm{Gd}_{3}, \mathrm{AlGd}, \mathrm{Al}_{2} \mathrm{Gd}$ and $\mathrm{Al}_{3} \mathrm{Gd}$, at temperatures below $650{ }^{\circ} \mathrm{C}$ which is higher than the experimental temperature range used in the present work, $450-550{ }^{\circ} \mathrm{C}$.

In order to identify the $\mathrm{Gd}-\mathrm{Al}$ alloys formed at the surface, two electrochemical techniques were used: 


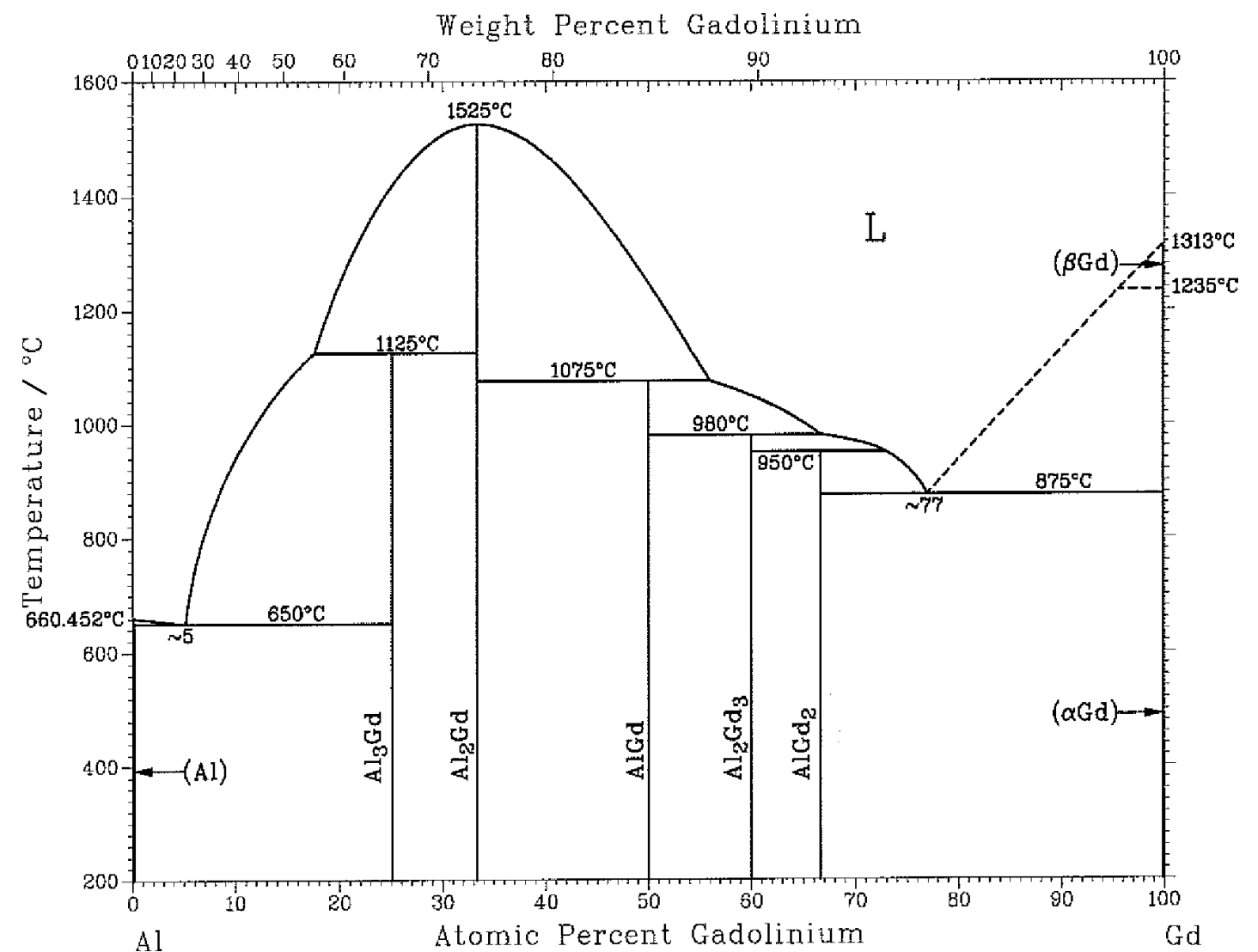

Fig. 1. Gd-Al phase diagram [12].

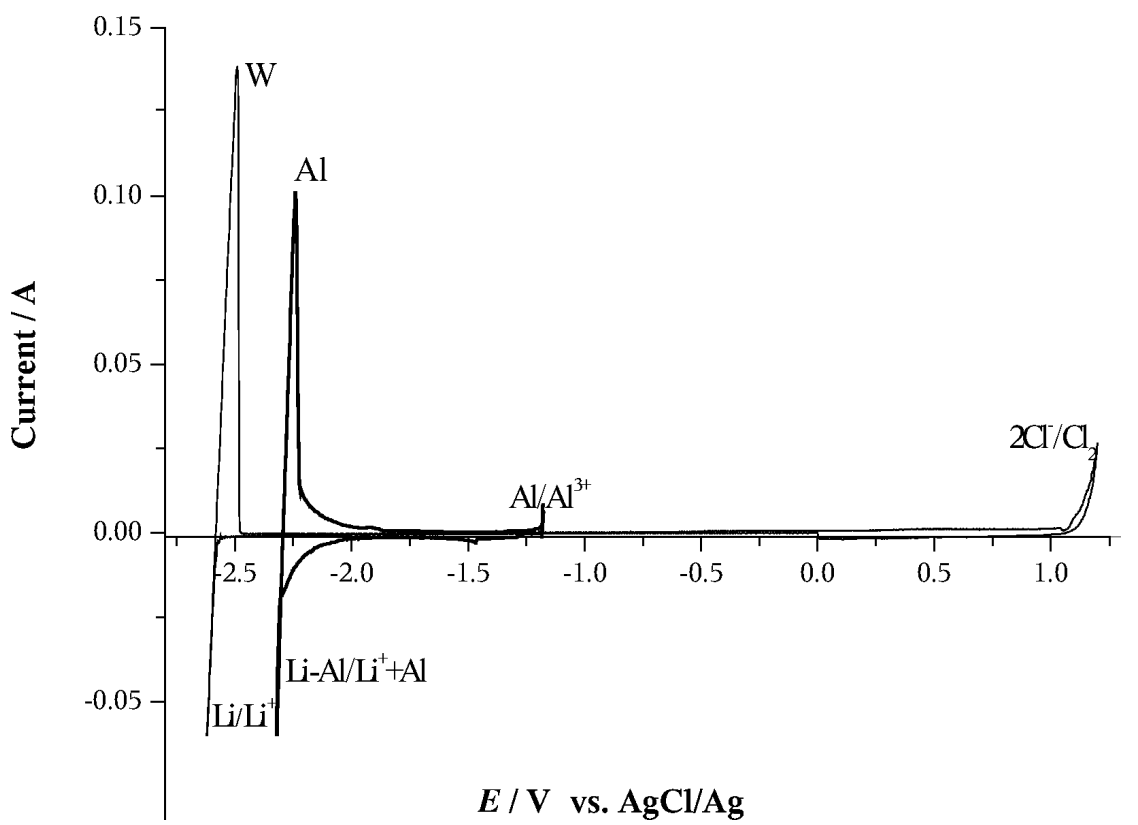

Fig. 2. Electrochemical window of the eutectic LiCl-KCl at $\mathrm{W}$ and $\mathrm{Al}(\varnothing 1 \mathrm{~mm})$ working electrodes; temperature, $723 \mathrm{~K}$; scan rate, $0.1 \mathrm{~V} \mathrm{~s}^{-1}$. 


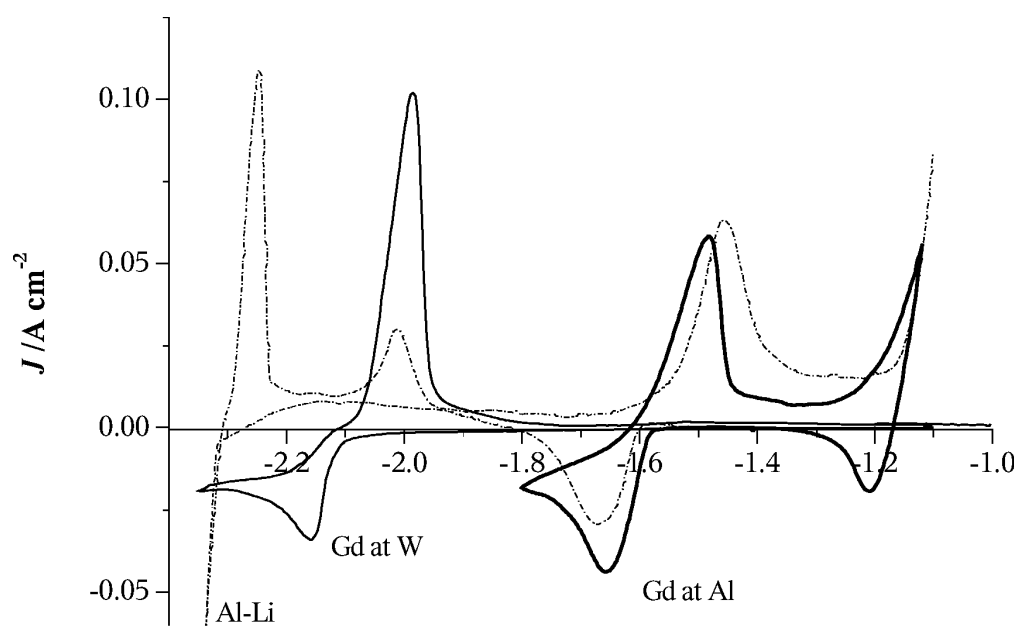

E / V vs. AgCl/Ag
Fig. 3. Cyclic voltammogram of Gd(III) at an inert W electrode $\left(S=0.22 \mathrm{~cm}^{2}\right)$ and at a reactive solid $\mathrm{Al}$ working electrode $\left(S=0.45 \mathrm{~cm}^{2}\right) ; \mathrm{Gd}^{3+}$ concentration, $6.0 \cdot 10^{-2} \mathrm{~mol} \mathrm{~kg}{ }^{-1}$; temperature, $733 \mathrm{~K}$; scan rate, $0.1 \mathrm{~V} \mathrm{~s}^{-1}$. open-circuit potentiometry (OCP) and cyclic voltammetry (CV). $\mathrm{A} \mathrm{GdCl}_{3}$ solution of $6.0 \cdot 10^{-2} \mathrm{~mol} \mathrm{~kg}^{-1}$ was used in the determination of equilibrium potentials of coexisting phases.

\subsection{Cyclic Voltammetry}

Figure 2 shows the electrochemical window of $\mathrm{LiCl}-$ $\mathrm{KCl}$ at $723 \mathrm{~K}$ at both $\mathrm{W}$ and $\mathrm{Al}$ electrodes. The cathodic limit that corresponds to the $\mathrm{Li}(\mathrm{I})$ reduction at the $\mathrm{W}$ working electrode is $-2.58 \mathrm{~V}$ vs. $\mathrm{AgCl} / \mathrm{Ag}$, whereas at the $\mathrm{Al}$ electrode the cathodic limit is the formation of the Li-Al alloy at $\sim-2.29 \mathrm{~V}$ vs. $\mathrm{AgCl} / \mathrm{Ag}$. A shift of the potential in the positive direction is observed when $\mathrm{Al}$ is used due to a decrease of the activity of $\mathrm{Li}(\mathrm{I})$ in $\mathrm{Al}$ as a consequence of the alloy formation.

The Gd-Al alloy formation was studied using the $\mathrm{CV}$ technique. A typical voltammogram of $\mathrm{Gd}^{3+}$ in $\mathrm{LiCl}-\mathrm{KCl}$ at an inert $\mathrm{W}$ working electrode is shown in Figure 3. The shape of the re-oxidation peak is characteristic for the deposition of a solid compound. The voltammogram also shows that the electrodeposition of $\mathrm{Gd}^{3+}$ on $\mathrm{Gd}$ metal requires to apply an overpotential, indicating that the process is affected by a nucleation phenomenon. This nucleation phenomenon has also been corroborated by the technique of chronoamperometry.

A voltammogram of $\mathrm{Gd}$ at a reactive $\mathrm{Al}$ electrode is also shown in Fig. 3; in this case, the electrodeposition occurs at a more positive potential. This potential shift, about $0.56 \mathrm{~V}$, is associated with a decrease of the activity of $\mathrm{Gd}$ in $\mathrm{Al}$ with respect to the activity of $\mathrm{Gd}$ at $\mathrm{W}$, produced by the formation of $\mathrm{Gd}-\mathrm{Al}$ alloys. The current of this peak is associated with a reaction of the following kind [13]:

$$
\mathrm{Gd}^{3+}+3 \mathrm{e}^{-}+x \mathrm{Al}=\mathrm{GdAl}_{x},
$$

where $x$ can take values given by the binary Gd-Al diagram of Figure 1.

No more peaks, neither cathodic nor anodic, have been observed when cyclic voltammograms were performed towards more negative potential values, as can be seen in Figure 3. The fact that the number of anodic peaks is smaller than the number of alloys in the Gd-Al phase diagram suggests that some of the reactions are very slow [10].

\subsection{Open-Circuit Chronopotentiometry}

Cyclic voltammetry can not be used to identify the intermetallic compounds, however, this is possible with the open-circuit chronopotentiometry technique. By this technique, after a short cathodic polarization $(30-120 \mathrm{~s})$ at potentials corresponding to the $\mathrm{Gd}$ metal electrodeposition, the open-circuit potential of the $\mathrm{Al}$ electrode is recorded versus time.

During the polarization, the Gd metal deposited reacts with the $\mathrm{Al}$ electrode surface and diffuses in its bulk. The surface composition varies from pure $\mathrm{Gd}$ metal to an alloy very rich in $\mathrm{Al}$, thus a gradual shift of the potential towards more positive values takes place 


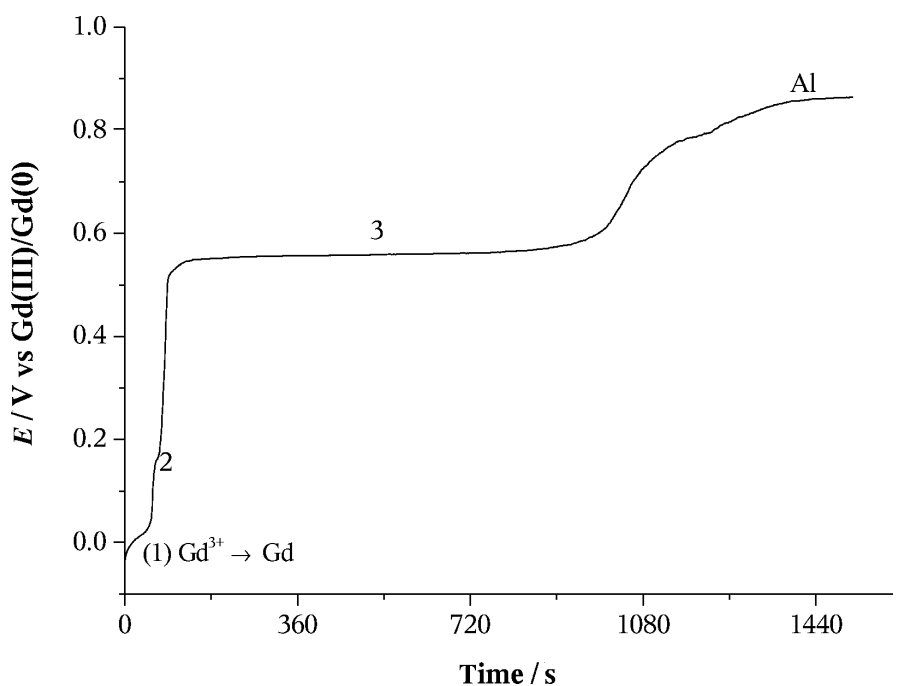

Fig. 4. Open-circuit chronopotentiogram of the $\mathrm{LiCl}-\mathrm{KCl}-\mathrm{GdCl}_{3}$ system at an $\mathrm{Al}$ electrode at $723 \mathrm{~K}$; counter electrode, vitreous carbon rod $(\varnothing 3 \mathrm{~mm})$; polarization time, $30 \mathrm{~s} ; E_{\mathrm{app}},-2.135 \mathrm{~V}$ vs. $\mathrm{AgCl} / \mathrm{Ag}$.
$[14,15]$. During this process, the curve presents potential plateaus corresponding to compositions of the electrode in which there is co-existence of two different phases.

The potential of these plateaus is given by the difference of the activity of $\mathrm{Gd}$ in the electrolyte, that is constant, and at the Gd-Al alloy surface, which is variable. As $\mathrm{Gd}$ diffuses into $\mathrm{Al}$ its concentration decreases at the electrode surface and the potential becomes more positive. When a two-phase equilibrium in the solid state exists at the surface of the electrode, the Gd activity is equal in each phase and remains constant while the Gd concentration decreases at the surface. This results in a constant potential plateau for a given diffusion time [13].

Figure 4 shows a potential-time curve obtained at $723 \mathrm{~K}$ for a molten bath containing $\mathrm{Gd}(\mathrm{III})$ at a concentration of $6.12 \cdot 10^{-2} \mathrm{~mol} \mathrm{~kg}^{-1}$. In this figure, three plateaus are observed before the abandon potential of $\mathrm{Al}$ [around $0.86 \mathrm{~V}$ vs. $\mathrm{Gd}(\mathrm{III}) / \mathrm{Gd}(0)$ ]. The first plateau corresponds to the Gd metal electrodeposition. A second plateau appears at about $0.16 \mathrm{~V}$ and a third plateau at around $0.56 \mathrm{~V}$, both vs. $\mathrm{Gd}(\mathrm{III}) / \mathrm{Gd}(0)$.

It has been observed that the potential of the second plateau depends on the polarization time and also on the pre-electrolysis potential applied. To study the latter effect, polarization at different potentials were tested. It has been observed that, if the pre-electrolysis is performed at potentials slightly more positive than the potential of $\mathrm{Gd}$ metal electrodeposition, the second plateau is not observed and only the plateau at about $0.56 \mathrm{~V}$ appears. This behaviour and the fact of the short length of the second plateau would indicate that the corresponding transformation reaction of one compound into the other is relatively slow [10]. Due to the difficulties of measuring the second plateau of Fig. 4, it was not taken into account for the thermodynamic properties determination; therefore only potentials corresponding to plateau 3 are going to be considered.

\subsection{Gd-Al Alloy Formation by Electrolysis}

In order to identify the composition of the different plateaus, potentiostatic electrolyses at values corresponding to potentials between the plateaus were performed at $450{ }^{\circ} \mathrm{C}$. Afterwards, the deposits were analyzed by XRD, EDX and SEM techniques. Al plates of $1 \mathrm{~mm}$ thickness were used in all the electrolyses. The potentials selected were: $-1.8 \mathrm{~V}$ (for 3 and $12 \mathrm{~h}$ ), $-2.0 \mathrm{~V}$ (for 2.5 and $3.5 \mathrm{~h}$ ) and $-2.2 \mathrm{~V}$ (for 2.5 and $3 \mathrm{~h}$ ); potential values were referred vs. $\mathrm{AgCl} / \mathrm{Ag}$. These values correspond to about $0.255,0.055$ and $-0.156 \mathrm{~V}$ vs. $\mathrm{Gd}(\mathrm{III}) / \mathrm{Gd}(0)$ at $450{ }^{\circ} \mathrm{C}$.

The diffractograms of the samples electrodeposited at $-1.80 \mathrm{~V}$ vs. $\mathrm{AgCl} / \mathrm{Ag}$, shown in Fig. 5a, indicate that the alloy formed consists of $\mathrm{GdAl}_{3}$, and that the deposit shows good crystallinity. Therefore, plateau 3 is identified as the following equilibrium [16]:

$$
3 \mathrm{Al}+\mathrm{Gd}^{3+}+3 \mathrm{e}^{-} \rightleftharpoons \mathrm{GdAl}_{3} .
$$

Diffractograms of the samples obtained by electrolysis performed at $-2.0 \mathrm{~V}$ vs. $\mathrm{AgCl} / \mathrm{Ag}$, see Fig. $5 \mathrm{~b}$, 

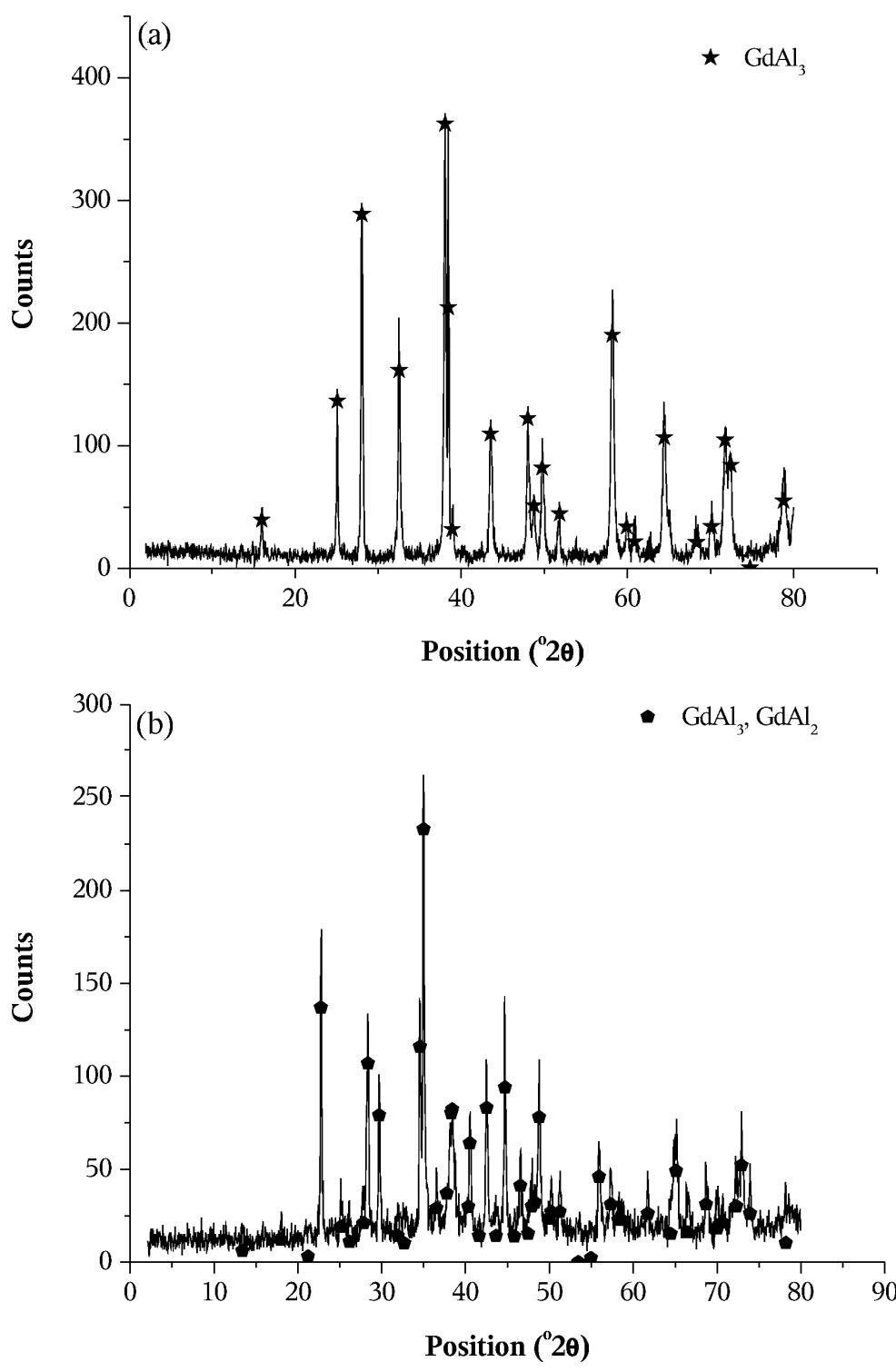

Fig. 5. (a) Diffractogram of a sample obtained by electrolysis at $-1.8 \mathrm{~V}$ vs. $\mathrm{AgCl} / \mathrm{Ag}$ for $7 \mathrm{~h}$, corresponding to the $\mathrm{GdAl}_{3}$ intermetallic compound. (b) Diffractogram of a sample obtained by electrolysis at $-2.0 \mathrm{~V}$ vs. $\mathrm{AgCl} / \mathrm{Ag}$ for $2.5 \mathrm{~h}$ at $723 \mathrm{~K}$, consisting of $\mathrm{GdAl}_{3}$ and $\mathrm{GdAl}_{2}$.

indicate the presence of the intermetallic compounds $\mathrm{GdAl}_{3}$ as main compound and $\mathrm{GdAl}_{2}$ as minor compound. Besides these two compounds, the presence of $\mathrm{LiCl}, \mathrm{KCl}$ and $\mathrm{GdOCl}$ is also observed in some of the samples. The presence of $\mathrm{GdOCl}$ is thought to be caused by the reaction of Gd metal deposited or some $\mathrm{GdCl}_{3}$ embedded in the salt with water during the sample washing. 2 is

Therefore, the equilibrium corresponding to plateau

$$
2 \mathrm{GdAl}_{3}+\mathrm{Gd}^{3+}+3 \mathrm{e}^{-} \rightleftharpoons 3 \mathrm{GdAl}_{2} .
$$

For electrolyses performed at $-2.2 \mathrm{~V}$ vs. $\mathrm{AgCl} / \mathrm{Ag}$, the compounds identified by XRD consist of $\mathrm{GdAl}_{3}$ and $\mathrm{GdAl}_{2}$. For this potential, the diffractograms obtained indicate that in this case $\mathrm{GdAl}_{2}$ is the main compound whereas $\mathrm{GdAl}_{3}$ is the minor compound.

It has been observed that after the electrolyses at the two more negative potentials, the Al plate was covered by a black mud that partly felt down when the sample was lifted up from the salt, and the rest disappeared during washing, settling at the bottom of the beaker as a black powder. Samples obtained at $-2.2 \mathrm{~V}$ presented a bigger black deposit. It is thought that the deposits 


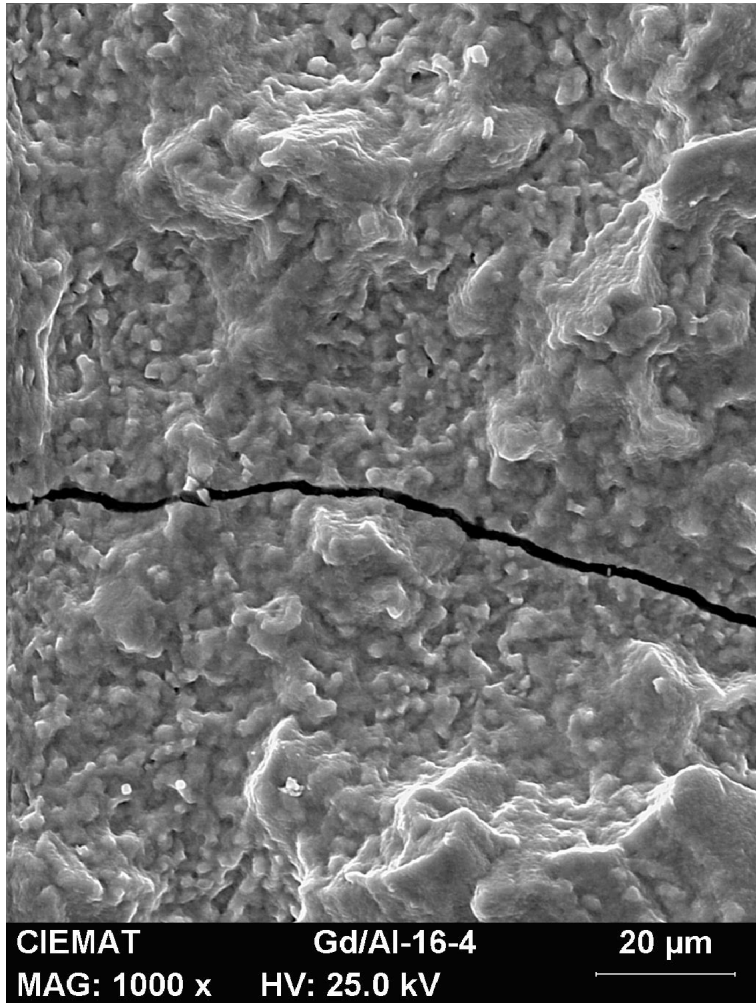

Fig. 6. Morphology of a deposit obtained by electrolysis at $-1.64 \mathrm{~V}$ vs. $\mathrm{AgCl} / \mathrm{Ag}$ at an $\mathrm{Al}$ plate for $7 \mathrm{~h}$ at $450{ }^{\circ} \mathrm{C}$ in $\mathrm{LiCl}-\mathrm{KCl}$.

could consist of some electrodeposited Li metal at the electrode surface.

Figure 6 shows the morphology of the surface of $\mathrm{GdAl}_{3}$, formed by potentiostatic electrolysis at $-1.64 \mathrm{~V}$ vs. $\mathrm{AgCl} / \mathrm{Ag}$ during $7 \mathrm{~h}$, obtained by SEM. The deposit is quite compact, although in the photograph it is possible to observe cracks. The compactness of the deposit can be appreciated more clearly in the cross-section of Figure 7. A quite homogeneous layer is observed along the surface of the Al plate, except for the edges, at which the thickness is slightly bigger. This edge effect is explained by a higher current flux than at the Al plate surface [17].

The corresponding surface composition obtained by EDX analysis indicates an average atomic composition of $73.11 \%$ of $\mathrm{Al}$ and $26.89 \%$ of $\mathrm{Gd}$ which agrees with the intermetallic, $\mathrm{GdAl}_{3}$, observed by XRD.

During the constant current electrolysis performed at $723 \mathrm{~K}$, the potential of the cathode and anode was recorded. The anodic potential was about $1.06 \mathrm{~V}$ vs. $\mathrm{AgCl} / \mathrm{Ag}$, that corresponds to $\mathrm{Cl}_{2}(\mathrm{~g})$ production. The chosen current values were low $(5-15 \mathrm{~mA})$, in or-

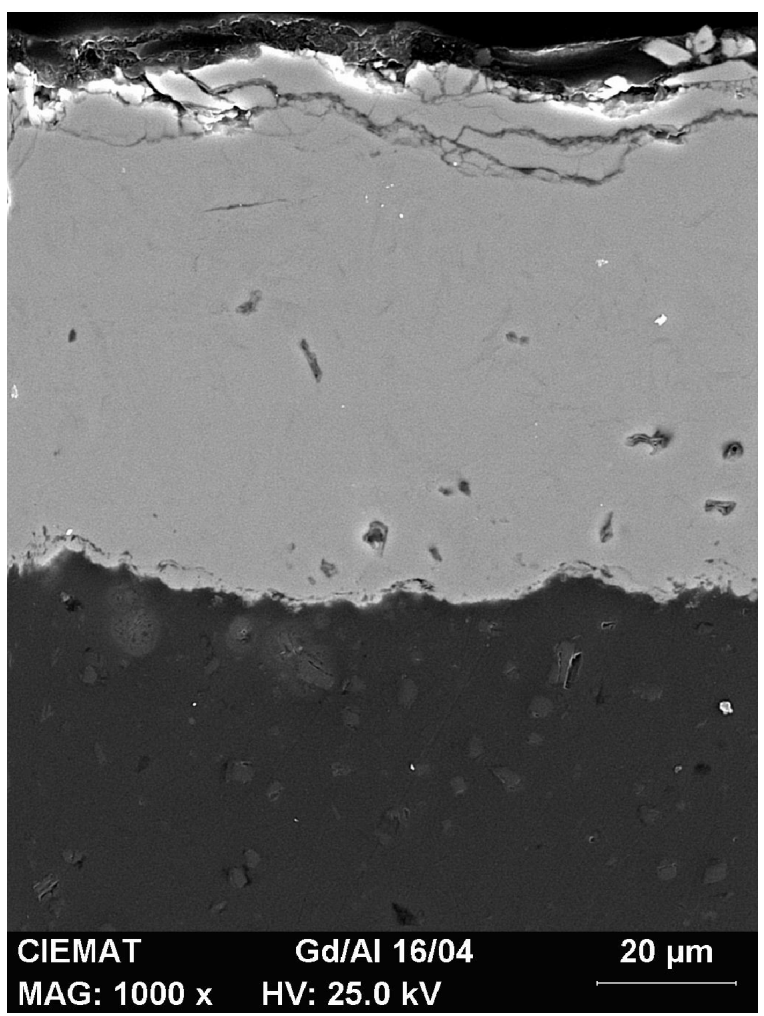

Fig. 7. Cross-section of a sample obtained by electrolysis at $-1.64 \mathrm{~V}$ vs. $\mathrm{AgCl} / \mathrm{Ag}$ for $7 \mathrm{~h}$ at an $\mathrm{Al}$ plate of $1 \mathrm{~mm}$ thickness, at $450{ }^{\circ} \mathrm{C}$. The average thickness of the compact layer obtained was $80 \mu \mathrm{m}$.

der to obtain cathodic potential values around the half peak potential value, $E_{\mathrm{P} / 2}$, of the corresponding $\mathrm{CV}$, and to avoid mass transport control. Under these conditions, only the $\mathrm{GdAl}_{3}$ intermetallic compound was identified by XRD. Preliminary cross-section measurements, performed by optical microscopy, indicated that galvanostatic electrolyses yield to thicker alloy layers than potentiostatic ones for similar times.

\subsection{Thermodynamic Property Determination}

If the potential plateau measured from the opencircuit potentiograms is expressed vs. the $\mathrm{Gd}(\mathrm{III}) /$ $\operatorname{Gd}(0)$ potential, the potential directly corresponds to an e.m.f. value for the two coexisting phases [14]. From these e. m. f. values several thermodynamic properties can be determined.

The $\mathrm{Gd}(\mathrm{III}) / \mathrm{Gd}(0)$ potential was determined by open-circuit chronopotentiometry, first at a $\mathrm{W}$ electrode and then at $\mathrm{Al}$ electrodes. Polarizations were performed at a potential corresponding to the Gd elec- 
Table 1. Thermodynamic properties of $\mathrm{Gd}$ in a $\mathrm{Gd}-\mathrm{Al}$ intermetallic compound in the two coexisting phases of $\mathrm{GdAl}_{3}$ and $\mathrm{Al}$.

\begin{tabular}{lccccc}
\hline$T / \mathrm{K}$ & $E / \mathrm{V}$ vs. $\mathrm{Gd}^{3+} / \mathrm{Gd}^{0}$ & $E / \mathrm{V}$ vs. $\mathrm{Gd}^{3+} / \mathrm{Gd}^{0}[9]$ & $\Delta \bar{G}_{\mathrm{Gd}} / \mathrm{kJ} \mathrm{mol}^{-1}$ & $\Delta \bar{G}_{\mathrm{Gd}} / \mathrm{kJ} \mathrm{mol}^{-1} \mathrm{at}^{-1}$ & $a_{\mathrm{Gd}}$ \\
\hline 723 & $0.562 \pm 0.003$ & $0.559 \pm 0.004$ & $-162.53 \pm 0.87$ & $-40.63 \pm 0.22$ & $(1.81 \pm 0.79) \cdot 10^{-12}$ \\
748 & $0.559 \pm 0.004$ & $0.556 \pm 0.002$ & $-161.83 \pm 2.03$ & $-40.46 \pm 0.51$ & $(5.00 \pm 0.60) \cdot 10^{-12}$ \\
773 & $0.557 \pm 0.002$ & $0.552 \pm 0.004$ & $-161.31 \pm 0.58$ & $-40.33 \pm 0.14$ & $(1.26 \pm 0.87) \cdot 10^{-11}$ \\
798 & $0.555 \pm 0.003$ & - & $-160.59 \pm 0.87$ & $-40.15 \pm 0.22$ & $(3.08 \pm 0.82) \cdot 10^{-11}$ \\
823 & $0.553 \pm 0.002$ & $0.546 \pm 0.002$ & $-160.06 \pm 0.29$ & $-40.02 \pm 0.07$ & $(6.73 \pm 0.94) \cdot 10^{-11}$ \\
\hline
\end{tabular}

trodeposition. Then, potential values corresponding to the plateau 3 were measured vs. $\mathrm{Gd}(\mathrm{III}) / \mathrm{Gd}(0)$, repeatedly in order to confirm the reproducibility. The corresponding average values obtained in this work are indicated in Table 1, for temperatures of 723-823 K, along with data found in the literature [9]. Discrepancies of potential values between our data and those of Bermejo et al. [9] vary from 3 to $7 \mathrm{mV}(0.5-1.2 \%)$, thus indicating a good agreement.

The relative molar partial Gibbs free energy of Gd in the $\mathrm{GdAl}_{3}$ intermetallic compound in two coexisting states, $\Delta \bar{G}_{\mathrm{Gd}}$, was calculated from the e. m. f. measurements $[E / \mathrm{V}$ vs. $\mathrm{Gd}(\mathrm{III}) / \mathrm{Gd}(0)]$, corresponding to the plateau 3 , by the equation [14]

$$
\Delta \bar{G}_{\mathrm{Gd}}=-3 F \Delta E .
$$

Thermodynamic data estimated this way are shown in Table 1. The relative molar enthalpy and entropy of Gd were also calculated from the Gibbs-Helmholtz equation. The expression obtained for this temperature dependence is

$$
\begin{aligned}
\Delta \bar{G}= & -180.48( \pm 1.64)+0.0249( \pm 0.0011) T \\
& (T / \mathrm{K}) .
\end{aligned}
$$

The e.m.f. corresponding to the alloy formed at the electrode surface is related to the activity of Gd by the following expression $[14,15]$ :

$$
\Delta E=\text { e.m.f. }=-\frac{R T}{n F} \ln a_{\mathrm{Gd}},
$$

where $a_{\mathrm{Gd}}$ is the activity of Gd in the alloy (Al). Values obtained with this expression are also given in Table 1. The obtained activity values indicate a low solubility of $\mathrm{Gd}$ in $\mathrm{Al}$.

[1] OCDE/NEA, Actinide and Fission Product Partitioning and Transmutation. Status and Assessment Report, OCDE Nuclear Agency, Paris 1999, pp. 27 -68.
The values of the relative molar partial Gibbs free energy of $\mathrm{Gd}$ in the $\mathrm{Gd}-\mathrm{Al}$ intermetallic compound and the activity determined in this work agree well with those found in the literature [9].

\section{Conclusions}

Electrochemical transient techniques, such as cyclic voltammetry and chronopotentiometry, have been used to identify the Gd-Al intermetallic compound formation in $\mathrm{LiCl}-\mathrm{KCl}$. The open-circuit potentiometry technique has also allowed to measure the e.m.f. values from the potential-time plateaus in order to determine the thermodynamic properties of two coexisting phases.

The two Gd-Al intermetallic compounds, identified by the surface analysis of the deposit formed by electrolysis at potential values between successive plateaus, were $\mathrm{GdAl}_{3}$ and $\mathrm{GdAl}_{2}$. The $\mathrm{Al}$ richer compound showed higher stability, longer plateau, which is in agreement with the literature reviewed. Due to the inaccuracy of potential values corresponding to the state of $\mathrm{GdAl}_{2}+\mathrm{GdAl}_{3}$ coexistence, thermodynamic properties have only been estimated for the $\mathrm{GdAl}_{3}$ intermetallic compound in the temperature range 723 $823 \mathrm{~K}$.

\section{Acknowledgements}

This work is part of a project performed at CIEMAT within the WP6 of the EUROPART project of the European Commission. The authors thank ENRESA for financial support within the agreement CIEMATENRESA, Annex X, about separation of long living radionuclides, No. 7800087. The authors also thank L. Gutiérrez, A. M. Lancha, A. del Rio, J. Quiñones, M. J. Tomás and M. Rosado for technical assistance.

[2] OCDE/NEA, Accelerator-Driven Systems (ADS) and Fast Reactors (FR) in Advanced Nuclear Fuel Cycles. A Comparative Study, OCDE Nuclear Agency, Paris 2002, pp. $15-23$. 
[3] V.A. Lebedev, Selectivity of Liquid Metal Electrodes in Molten Halides, Metallurgiya, Chelyabinsk, Moscow 1993 (in Russian and English translation).

[4] J. Serp, R. Malmbeck, and J.-P. Glatz, 7th International Symposium on Molten Salts Chemistry \& Technology, Toulouse, France, 29 August - 2 September 2005, p. 577.

[5] C. Caravaca, G. de Córdoba, M. J. Tomas, and M. Rosada, J. Nucl. Mater. 360, 25 (2007).

[6] F. Lantelme and Y. Berghoute, J. Electrochem. Soc. 146, 4137 (1999).

[7] S.P. Fusselman, J. J. Roy, D. L. Grimmett, L.F. Grantham, C. L. Krueger, C. R. Nabelek, T. S. Storvick, I. Tadashi, H. Takatoshi, K. Kensuke, S. Yoshiharu, U. Koichi, K. Tsutomu, and T. Noriaki, J. Electrochem. Soc. 146, 2573 (1999).

[8] J. J. Roy, L. F. Grantham, L. R. McCoy, C. L. Krueger, T. S. Storvic, T. Inoue, H. Miyashiro, and N. Takahashi, Mater. Sci. Forum 73-75, 547 (1991).

[9] M. R. Bermejo, J. Gomez, J. Medina, A. M. Martinez, and Y. Castrillejo, J. Electroanal. Chem. 588, 253 (2006).

[10] T. Nohiro, H. Kambara, K. Amezawa, and Y. Ito, J. Electrochem. Soc. 152, C183 (2005).

[11] C. Colinet, A. Pasturel, and K. H. J. Buschow, Physica B+C 150, 397 (1988).

[12] K. A. Gschneidner and F. W. Calderwood, Bull. Alloy Phase Diagrams 9, 6 (1988).

[13] L. Massot, P. Chamelot, and P. Taxil, Electrochim. Acta 50, 5510 (2005).

[14] H. Konishi, T. Nishikiori, T. Nohira, and Y. Ito, Electrochim. Acta 48, 1403 (2003).

[15] G. D. Picard, Y. E. Mottot, and B. L. Trémillon, Proc. Electrochem. Soc. 84, 585 (1984).

[16] P. Taxil, J. Less-Common Met. 113, 89 (1985).

[17] D. Pletcher, Lecture 7. Potential and current distributions in electrochemical cells. Summer School on Electrochemistry, Electrochemical Engineering and Electrochemical Technology, Southhampton University, UK 2006. 